\title{
Correction to: Genetic algorithms identify individuals with high risk of severe liver disease caused by schistosomes
}

\author{
Hélia Dessein ${ }^{1,2} \cdot$ Nicolas Duflot $^{1,2} \cdot$ Audrey Romano $^{1,2} \cdot$ Christopher Opio $^{3} \cdot$ Valeria Pereira $^{4} \cdot$ Carla Mola $^{4}$. \\ Narcis Kabaterene ${ }^{5} \cdot$ Ana Coutinho $^{6} \cdot$ Alain Dessein $^{1,2}$ (B)
}

Published online: 22 May 2020

○) Springer-Verlag GmbH Germany, part of Springer Nature 2020

\section{Correction to: Human Genetics \\ https://doi.org/10.1007/s00439-020-02160-4}

In the original article publication, the affiliation of the author Ana Coutinho is incorrect. The correct affiliation is Hospital das Clinicas, Av Prof Moraes Rego. Universidade Federal de Pernambucco. Recife PE CEP 50670420.

Publisher's Note Springer Nature remains neutral with regard to jurisdictional claims in published maps and institutional affiliations.

The original article can be found online at https://doi.org/10.1007/ s00439-020-02160-4.

Alain Dessein

alain.dessein@bilhigenetics.com

1 BILHI Genetics, 60 Avenue André Roussin, 13016 Marseille, France

2 UMR_S906-Génétique Et Immunologie Des Maladies Parasitaires, Aix Marseille Université-INSERM, Marseille, France

3 Department of Medicine, Mulago Hospital, Makerere University College of Health Sciences, Kampala, Uganda

4 Instituto Aggeu Magalhães, Fiocruz, Fundaçao Oswaldo Cruz, Av. Professor Moraes Rego, S/N Cidade Universitária, Recife, PE 50740-465, Brazil

5 Vector Control Division Uganda, Ministry of Health, Queen's Ln, Kampala, Uganda

6 Hospital das Clinicas, Cidade Universitaria, Av Prof Moraes Rego, Recife, PE CEP 50670420, Brazil 